\title{
PENGARUH PENGEMBANGAN PERKANTORAN DAN APARTEMEN DI JALAN TB. SIMATUPANG, JAKARTA SELATAN TERHADAP PERUBAHAN PERUMAHAN SEKITAR
}

\author{
Khrisnanda Prawira ${ }^{1)}$, Suryono Herlambang ${ }^{2)}$, Parino Rahardjo ${ }^{3)}$ \\ 1)Program Studi S1 PWK, Fakultas Teknik, Universitas Tarumanagara, prawirakhrisnanda@gmail.com \\ 2)Program Studi S1 PWK, Fakultas Teknik, Universitas Tarumanagara, s.herlambang@gmail.com \\ 3)Program Studi S1 PWK, Fakultas Teknik, Universitas Tarumanagara, parinor19@gmail.com
}

Masuk: 10-08-2020, revisi: 09-09-2020, diterima untuk diterbitkan: 25-09-2020

\begin{abstract}
Abstrak
Kawasan TB Simatupang Koridor Persimpangan Pondok Pinang - Persimpangan Fatmawati memiliki pertumbuhan property yang sangat pesat, secara umum diisi oleh sector perminyakan dan gas sehingga mengundang banyak pekerja asing. Perkembangan ini memberikan pengaruh besar bagi sector poroperty. Beberapa wilayah di sekitar terkena dampak dari tingginya perkembangan di wilayah induk ini. Tingginya perkembangan pada daerah ini dikhawatirkan dapat mengakibatkan dampak negative terhadap pemukiman sekitar. Penetapan segmen Persimpangan Pondok Pinang-Persimpangan Fatmawati ini dimaksudkan untuk membatasi fokus obyek penelitian agar pelaksanaan penelitian dapat dilakukan dengan lebih detail. Pada segmen ini banyak berkembang bangunan komersil seperti apartment, shopping mall, bangunan perkantoran dan bangunan bangunan komersil lainnya. Studi ini dilakukan menggunakan metode deduktif kualitatif. Perkembangan kawasan yang sangat pesat perlu diperhatikan agar tidak memberikan dampak negative terhadap lingkungan sekitar di masa depan. Penelitian ini dilakukan bertujuan untuk mengetahui apakah terdapat pengaruh yang diakibatkan oleh perkembangan Kawasan office dan apartment di kawasan TB Simatupang Koridor Persimpangan Pondok Pinang - Persimpangann Fatmawati, Menguraikan dampak apa saja yang terjadi akibat perkembangan kawasan TB Simatupang Koridor Persimpangan Pondok Pinang - Persimpangan Fatmawati terhadap permukiman sekitar. Dengan menggunakan metode Pengumpulan data dapat dilakukan secara primer dan sekunder. Metode tersebut diharapkan dapat memenuhi tujuan dari penelitian ini.
\end{abstract}

Kata Kunci: koridor TB Simatupang; peningkatan fungsi komersial dan perkantoran; perubahan fungsi kawasan perumahan

\begin{abstract}
TB Simatupang area koridor Crossroads of Pondok Pinang until Crossroads of Fatmawati has a very rapid property growth, generally filled by the oil and gas sector thus inviting many foreign workers. This development has a big influence on the property sector. Some of the surrounding areas are affected by the high development in this parent region, it is feared that the high development in this area could have a negative impact on the surrounding settlements. Segment determination of Crossroads of Pondok Pinang until Crossroads of Fatmawati intended to limit the focus of research objects so that the implementation of research can be done in more detail. In this segment many developing commercial buildings such as apartments, shopping malls, office buildings and other commercial buildings. This study was conducted using a qualitative deductive method. The rapid development of the region needs to be considered so they not make negatively impact the surrounding environment in the future. This research aims to determine whether ther is an influence caused by the development of the office and apartment area in TB Simatupang area koridor Crossroads of Pondok Pinang until Crossroads of Fatmawati describe what impacts have occurred dnue to regional development. Describe what impacts will accur due to the development of the area TB Simatupang area koridor Crossroads of Pondok Pinang until Crossroads of Fatmawati against the surrounding settlements. By using data collection
\end{abstract}


methods can be done primary and secondary. This method is expected to fulfill the purpose of the research.

Keywords: change of residential landuse; increasing commercial and office use; TB Simatupang corridor

\section{PENDAHULUAN}

\section{Latar Belakang}

Kawasan TB Simatupang memiliki pertumbuhan property yang sangat pesat. Salah satu produk property ini adalah perkantoran. Menurut Colliers International Indonesia, pasokan perkantoran di TB Simatupang mencapai 833,899 $\mathrm{m}^{2}$. Luasan ini setara dengan $50 \%$ dari seluruh pasokan perkantoran di Jakarta Selatan. Secara umum ruang kantor di TB Simatupang diisi oleh sektor perminyakan dan gas, sehingga secara tidak langsung turut mengundang banyak pekerja asing. Pekerja asing lebih suka tinggal di apartemen, sehingga apartemen juga tumbuh pesat di jalur TB Simatupang.

Perkembangan akses transportasi massal ikut mendorong perkembangan kawasan TB Simatupang. Beroperasinya MRT dan adanya jalur Trans Jakarta yang melewati koridor Simatupang memiliki peran besar dalam perkembanan koridor Simatupang. Jalur tol lingkar luar yang berdampingan dengan Jalan TB Simatupang juga merupakan faktor penting perkembangan kawasan.

Perubahan yang terjadi di TB Simatupang memberikan pengaruh besar bagi sektor properti. Beberapa wilayah di sekitar TB Simatupang ikut terkena imbas karena tingginya perkembangan di kawasan induk ini. Kawasan sekitar yang terkena imbas ini adalah Ampera, Fatmawati, Tanjung Barat, Pasar Rebo, yang posisi lokasnya berhimpitan langsung dengan koridor TB Simatupang.

Penetapan segmen Persimpangan Pondok Pinang - Persimpangan Fatmawati ini dimaksudkan untuk membatasi fokus obyek penelitian agar pelaksanaan penelitian bisa lebih detail. Pada segmen ini banyak bekembang bangunan komersil seperti apartement, shopping mall, bangunan perkantoran dan bangunan-bangunan pusat bisnis lainnya.

\section{Rumusan Masalah}

Perkembangan office dan apartment yang cepat di jalan TB Simatupang koridor Persimpangan Pondok Pinang - Persimpangan Fatmawati dikhawatirkan dapat mengakibatkan dampak negatif terhadap permukiman sekitar. Perkembangan office dan apartment akan menarik pergerakan orang untuk bekerja di dalam kawasan ini. Orang akan cenderung memilih tempat tinggal yang dekat dengan tempat mereka bekerja. Selain itu, banyaknya kegiatan office dan berkembangntya apartment juga meningkatkan permintaan kebutuhan layanan untuk orangorang yang berakitivitas di dalam kawasan, utamanya adalah kebutuhan makan, minum, dan jasa layanan lainnya. Faktor-faktor ini akan menarik orang untuk datang dan bertempat tinggal di dalam atau sekitar kawasan.

\section{Tujuan}

Melihat perkembangan Kawasan office dan apartment di kawasan TB Simatupang Koridor Persimpangan Pondok Pinang - Persimpangan Fatmawti, mengetahui apakah terdapat pengaruh yang diakibatkan oleh perkembangan Kawasan office dan apartment di kawasan TB Simatupang Koridor Persimpangan Pondok Pinang - Persimpangan Fatmawati, menguraikan dampak apa saja yang terjadi akibat perkembangan kawasan TB Simatupang Koridor Persimpangan Pondok Pinang - Persimpangan Fatmawati terhadap permukiman sekitar. 


\section{KAJIAN LITERATUR}

Pertumbuhan perkotaan di Indonesia, khususnya di wilayah DKI Jakarta secara fisik ditandai dengan pertumbuhan yang cepat di pinggiran kota, membentuk daerah permukiman baru dimana pertumbuhannya cenderung meluas dan tersebar secara acak tidak terkendali. Daerah pinggiran kota adalah zona transisi yang berada dalam proses tekanan perkotaan, mengakibatkan terjadin kondisi degradasi lingkungan (Hidayat et. al. 2013). Perubahan permukiman dapat dipengaruhi oleh aktivitas penduduk di dalamnya. Perubahan bentuk bangunan rumah dapat diihat dari tampak bangunan, jumlah lantai bangunan, luas bangunan dan fungsi bangunan, baik di dalam maupun di luar bangunan (Rappoport, 1969). Terdapat 3 aspek yang dapat dijadikan sebagai tolok ukur untuk melihat perubahan lingkungan fisik permukiman (Habaraken, 1978) yaitu: Sistem spasial mencakup ruang, orientasi ruang, dan pola hubungan ruang (pola spasial ruang), Sistem fisik berkaitan dengan konstruksi, penggunaan material seperti konstruksi atap, dinding, dan lantai, Sistem model meliputi fasade, bentuk pintu dan jendela, serta unsur-unsur lain, baik di dalam maupun di luar bangunan. Hasil penelitian Winarendri dan Khadiyanta (2015) di Semarang menunjukkan bahwa kecenderungan perubahan usaha pada kawasan permukiman pada sekitar kakwasan komersil adalah menjadi kos-kosan seperti yang ditunjukkan pada tabel 1 dibawah ini.

Tabel 1. Kecenderungan Perubahan Fungsi Bangunan di Semarang

\begin{tabular}{cccccc}
\hline \multirow{2}{*}{ Pemilik Usaha } & \multicolumn{5}{c}{ Keinginan Pengembangan } \\
\cline { 2 - 5 } & Kos-kosan & Toko & Restoran & Warung & Laundry \\
\hline Warung Kecil & $\checkmark$ & $\checkmark$ & & $\checkmark$ \\
\hline Kos-kosan & & & $\checkmark$ & \\
\hline Toko & $\checkmark$ & & \\
\hline Warung Makan & $\checkmark$ & & \\
\hline Laundry & $\checkmark$ & & \\
\hline
\end{tabular}

Sumber : WInarendri dan Khadayanta, 2015

Perkembangan kawasan komersil terhadap kawasn permukiman dipengaruhi oleh jarak atau kedekatan jarak antara kawasan komersil dengan kawasn permukiman seperti tersaji pada Gambar 1. Semakin dekat dengan kawasan komersil, pengaruh perkembangan kawasan komersil terhadap kawasan permukiman semakin kuat. Sebaliknya semakin jauh jarak antara kawasan komersil dengan kawasan permukiman, hubungan keterkaitannya semakin kecil atau bahkan tidak ada.

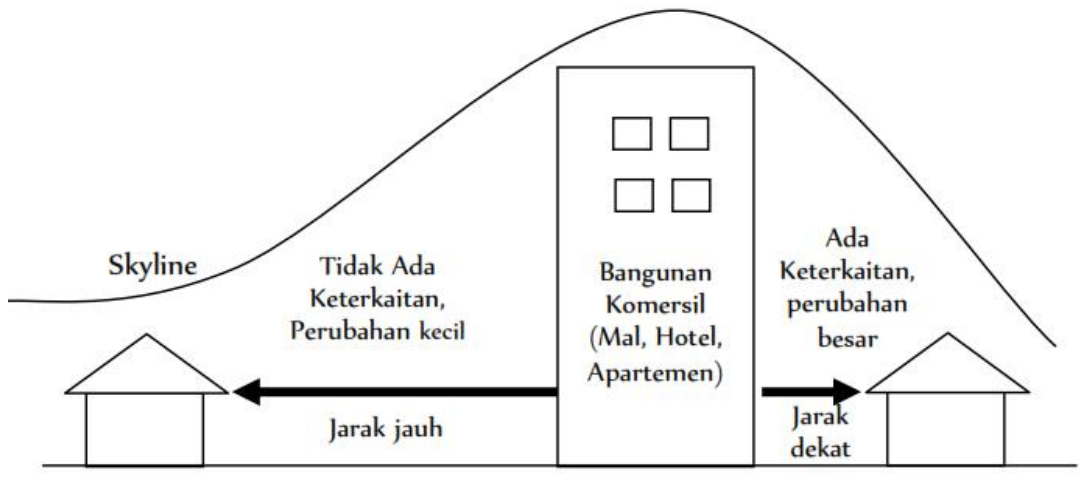

Gambar 1. Keterkaitan Perkembangan Kawsan Komersil dengan Kawasan Permukiman Sumber : WInarendri dan Khadayanta, 2015

Winarendri dan Kadhayanta (2015) membagi perubahan pola lingkungan permukiman ke dalam 4 tingkatan yaitu perubahan sangat besar, perubahan besar, perubahan sedang, dan perubahan kecil. Hasil pengamatan di kawasan Jalan Gajahmada dan Jalan Thamrin di Semarang adalah seperti disajikan pada Gambar 2 dibawah. 


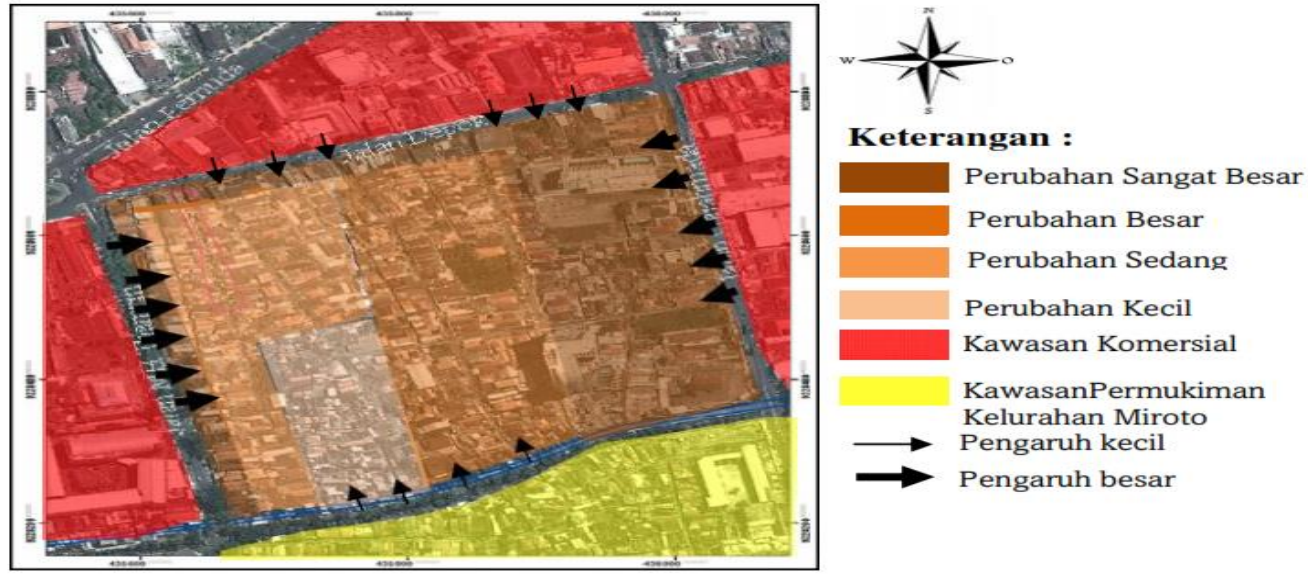

Gambar 2. Tingkat Perubahan Kawasan Permukiman

di Kelurahan Kembangsari, Kota Semarang

Sumber : Winarendri dan Kadhayanta. 2015

Perkembangan kawasan komersil member pengaruh pada perubahan karakteristik penduduk yang dilihat dari perubahan jenis pekerjaan, tingkat penghasilan dan status kepemilikan. Perkembangan kawasan juga memberikan dorongan perkembangan aktivitas pendukung seperti kos-kosan, warung makan, toko/warung, laundry, dan jasa lainnya. Perubahan bangunan rumah dipengaruhi oleh tingkt perekonomian penduduk, arah hadap rumah terhadap jalan besar, dan kedekatan terhadap bangunan komersil. Pengaruh lain yang ditimbulkan dari kawasn komersil adalah semakin ramainya kawasan permukiman, berkurangnya kenyamanan dalam bermukim, kemacetan lalu lintas, dan samakin rmainya kegiatan ritel.

\section{METODE}

Penelitian dilakukan di Jakarta, sedangkan obyek penelitian adalah Jalan TB Simatupang ruas Persimpangan Pondok Pinang - Persimpangan Fatmawati. Persimpangan Pondok Pinang masuk Kelurahan Pondok Pinang, Kecamatan Kebayoran Lama, dan Persimpangan Fatmawati masuk Kelurahan Cilandak barat, Kelurahan Cllandak.

Pengumpulan data dapat dilakukan secara primer dan sekunder. Pengumpulan data primer dilakukan dengan menggunakan dua teknik pengumpulan data seperti Observasi lapangan merupakan teknik pengumpulan data yang bertujuan untuk mendapatkan data primer dengan cara mengamati langsung objek yang diteliti untuk menemukan suatu proses dan kondisi yang terjadi sesuai kenyataan di lapangan. Dan wawancara yang merupakan bentuk komunikasi verbal atau percakapan yang bertujuan memperoleh infromasi dengan mengajukan beberapa pertanyaan kepada narasumber yang terpercaya.

Sedangkan untuk data sekunder, pengumpulannya dilakukan dengan dua teknik pengumpulan data yaitu antara lain: Dokumentasi yang merupakan pengumpulan dokumen - dokumen administratif, artikel, agenda rapat, maupun dokumen - dokumen yang terkait dengan penelitian. Dan Rekaman arsip yang merupakan teknik pengumpulan data baik data historis maupun data saat ini. Jenis data, sumber data, dan metode pengumpulannya disajikan pada Tabel 2.

Tabel 2. Jenis, Sumber, dan Metode Pengumpulan Data

\begin{tabular}{clll}
\hline No. & \multicolumn{1}{c}{ Jenis Data } & \multicolumn{1}{c}{ Sumber Data } & Metode Pengumpulan \\
\hline \multirow{2}{*}{1} & $\begin{array}{l}\text { Batas wilayah } \\
\text { administrasi }\end{array}$ & $\begin{array}{l}\text { Dinas Cipta Karya dan Tata } \\
\text { Ruang Provinsi DKI Jakarta }\end{array}$ & $\begin{array}{l}\text { Diunduh dari portal } \\
\text { dcktrp.jakarta.go.id }\end{array}$
\end{tabular}




\begin{tabular}{|c|c|c|c|}
\hline No. & Jenis Data & Sumber Data & Metode Pengumpulan \\
\hline 2 & $\begin{array}{l}\text { Zonasi Pemanfaatan } \\
\text { Ruang dan RDTR }\end{array}$ & $\begin{array}{l}\text { Dinas Cipta Karya dan Tata } \\
\text { Ruang Provinsi DKI Jakarta }\end{array}$ & $\begin{array}{l}\text { Diunduh dari portal } \\
\text { dcktrp.jakarta.go.id }\end{array}$ \\
\hline 3 & $\begin{array}{l}\text { Perkembangan } \\
\text { bangunan Office dan } \\
\text { Apartment }\end{array}$ & Lapangan & $\begin{array}{l}\text { Wawancara dengan karyawan gedung } \\
\text { Analisis spasial }\end{array}$ \\
\hline 4 & $\begin{array}{l}\text { Sarana prasarana } \\
\text { lingkungan }\end{array}$ & Lapangan & $\begin{array}{l}\text { Observasi lapangan untuk melihat } \\
\text { kondisi fisik keberadaan bangunan } \\
\text { sarana prasarana lingkungan }\end{array}$ \\
\hline 5 & Kependudukan & BPS Jakarta Selatan & Unduh dari portal jakselkota.bps.go.id \\
\hline 6 & $\begin{array}{l}\text { Fisik bangunan } \\
\text { perumahan }\end{array}$ & Lapangan & $\begin{array}{l}\text { Observasi untuk melihat kondisi fisik } \\
\text { bangunan perumahan }\end{array}$ \\
\hline 7 & $\begin{array}{l}\text { Pekembangan } \\
\text { bangunan perumahan }\end{array}$ & Lapangan & $\begin{array}{l}\text { Observasi untuk melihat kondisi } \\
\text { perkembangan bangunan perumahan } \\
\text { Wawancara dengan penduduk } \\
\text { setempat }\end{array}$ \\
\hline
\end{tabular}

Sumber: olahan penulis, 2020

Metode analisis data menjawab tujuan penelitian dan mengetahui bagaimana perkembangan kawasan perumahan di Kelurahan Pondok Pinang dan Kelurahan Cilandak Barat akibat perkembangan office dan apartemen di Jalan TB SImatupang ruas Persimpangan Pondok Pinang - Persimpangan Fatmawati.

\section{DISKUSI DAN HASIL}

\section{Peningkatan Aksesibilitas}

Pada periode Tahun 2010 - 2020, koridor Jl. TB. Simatupang Ruas Permpatan Pondok Pinang Perempatan Fatmawati mengalami peningkatan yang sangat nyata. Pada Tahun 2014 mulai beroperasi moda transportasi massal bus Trans Jakarta, dan Tahun 2019 mulau beroperasi modal transportasi massal Moda Raya Terpadu (MRT). Bus Trans Jakarta menghubungkan kea rah Grogol, Harmoni, Blok M, Senen, Kampung Rambutan. Sementara itu Modal Raya Terpadu menghubungkan Terminal Lebak Bulus sampak dengan Terminal Hotel Indonesia melalui jalur Jalan Raya Fatmawati kearah Blok M, Jl. Sudirman, hingga Hotel Indonesia. Trans Jakarta Koridor Lebak Bulus-Harmoni melewati Jalur Pondok Pinang, Pondok Indah, Jalan Panjang, Jl. Daan Mogot, Jl. S. Parman, Jl. Tomamg Raya, Petojo, dan Harmoni, seperti disajikan pada Gambar 25. Sementara itu jalur MRT secara rinci adalah mulai dari Lebak Bulus, kemudian Fatmawati, Cipete Raya, Haji Nawi, B;ok A, Blok M, Sisingamangaraja, Senayan, Istora, Benhil, Setiabudhi, Dukuh Atas, dan trekahir Hotel Indonesia

\section{Perkembangan Kependudukan}

Pertumbuhan penduduk adalah perubahan jumlah penduduk, baik berupa pertambahan maupun perurunan. Pertumbuhan penduduk di suatu wilayah dipengaruhi oleh besarnya kelahiran, kematiaj, migrasi masuk, dan migrasi keluar. Pada batas-batas tertentu, pertumbuhan penduduk dapat juga menggambarkan pertumbuhan kota.

Pertumbuhan Penduduk Kelurahan Pondok Pinang Data jumlah penduduk periode Tahun 20092018 tidak lengkap dan tidak menunjukkan pola yang jelas. Jumlah penduduk $\mathrm{t}=$ Tahun 2012 turun dibandingkan dengan jumlah penduduk Tahun 2010. Demikian pula jumlah penduduk Tahun 2018 juga menurun dibandingkan dengan jumlah penduduk tahun sebelumnya yaitu Tahun 2017. Untuk melihat pertambahan penduduk selama periode Tahun 2009 dengan Tahun 2018, dilakukan dengan cara mengurangkan jumlah penduduk Tahun 2009 terhadap jumlah penduduk Tahun 2018. Dengan metode ini bisa diperoleh gambaran rata-rata pertambahan 
jumlah penduduknya yaitu sebanyak 16,073 jiwa selama periode 9 tahun. Bila dilihat presentasenya terhadap jumlah penduduk awal yaitu Tahun 2009, pertambahan selama 9 tahun ini adalah sebesar $31 \%$.

Bila diihat rata-rata pertambahan per tahun selama periode 9 tahun tersebut, diperoleh hitungan pertambvahan rata-rata jumlah penduduk per tahun adalah sebesar 1,786 jiwa atau sebesar rata-rata 3\%. Angka pertambahan penduduk sebesar 3\% ini jauh lebih besar dibandingkan dengan angka pertumbuhan penduduk DKI Jakarta Tahun 2010-2019 sebesar 1.19\% (BPS DKI Jakarta, 2020).

Pertumbuhan Penduduk Kelurahan Cilandak Barat, Kelurahan Cilandak Barat memiliki angka pertambahan jumlah penduduk yang sangat kecil yaitu hanya rata-rata $0.77 \%$ per tahun. Angka ini jauh lebih kecil dibandingkan dengan angka pertumbuhan penduduk DKI Jakarta Tahun 20102019 yang mencapai 1.19\% seperti yang telah disebutkan di atas. Bila dilihat dari keberadaan bangunan apartemen, Kelurahan Cillandak Barat juga memiliki bangunan apartemen seperti halnya Kelurahan Pondok Pinang.

\section{Rencana Detail Tata Ruang (RDTR)}

Pada Gambar 3 dan 4 terlihat fungsi ruang di koridor Jl. TB. Simatupang ruas Perempatan Pondok Pinang - Perempatan Fatmawati adalah untuk area komeril dan bangunan fasilitas umum. Jenisjenis penggunaan komersil adalah untuk pembangunan perkantoran, area perdagangan, dan jasa. Fasilitas umum dan sosial yang ada di koridor ini adalah gedung universitas dan bangunan kantor camat.

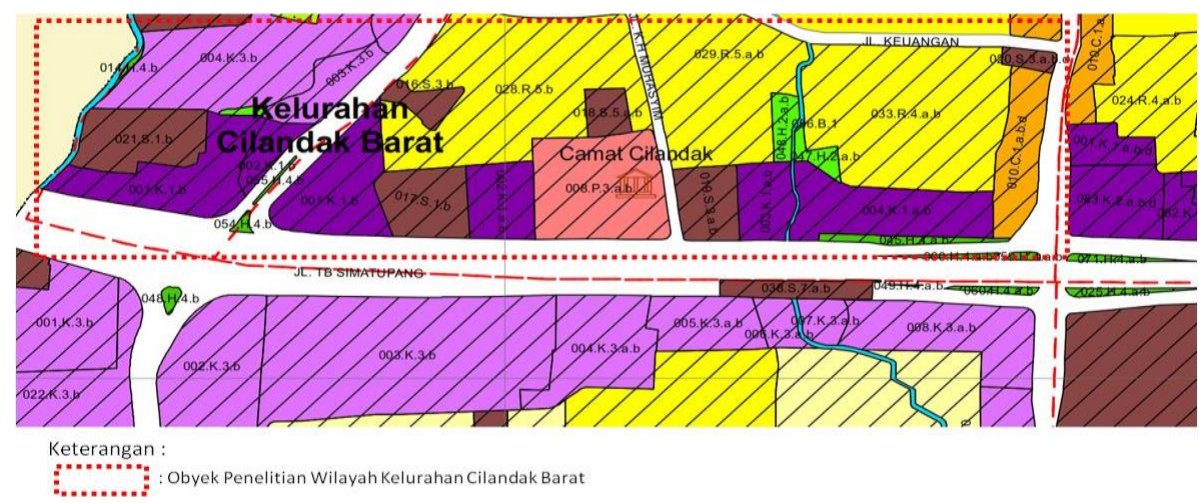

Gambar 3. RDTR Kecamatan Cilandak, Bagian Kawasan Kelurahan Cilandak Barat Sumber: RDTR DKI Jakarta 2030

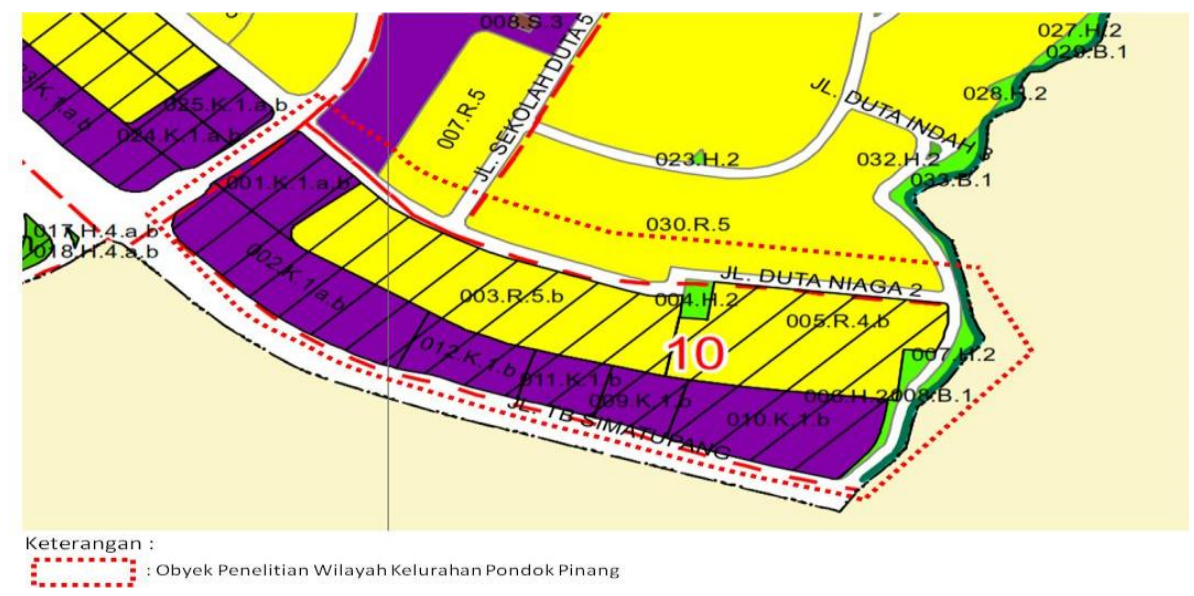

Gambar 4. RDTR Kecamatan Kebayoran Lama, Bagian Kawasan Kelurahan Pondok Pinang Sumber: RDTR DKI Jakarta 2030 
Tabel 3. Zonasi dan Intensitas Bangunan Wilayah Study

\begin{tabular}{|c|c|c|c|c|c|c|c|c|}
\hline ID Sub Blok & Zona & KDB & KLB & KB & KDH & КTB & Tipe & PSL \\
\hline \multicolumn{9}{|c|}{ Kelurahan Cilandak Barat, Kecamatan Cilandak } \\
\hline 021.S.1.b & Pelayanan umum dan sosial & 40 & 3.0 & 16 & 35 & 50 & $\mathrm{~T}$ & $\mathrm{KP}$ \\
\hline 002.K.1.b & Perdagangan dan jasa & 45 & 3.0 & 16 & 35 & 50 & $\mathrm{~T}$ & $\mathrm{KP}$ \\
\hline 001.K.1.b & Perkantoran Perdagangan dan Jasa & 40 & 3.0 & 16 & 35 & 50 & $\mathrm{~T}$ & KP \\
\hline 017.s.1.b & Pelayanan umum dan sosial & 40 & 3.0 & 16 & 35 & 50 & $\mathrm{~T}$ & KP \\
\hline 002.K.1.a.b & Perkantoran perdagangan dan jasa & 45 & 3.0 & 16 & 35 & 50 & $\mathrm{~T}$ & $\mathrm{KP}$ \\
\hline 008.P.3.a.b & Pemerintahan daerah & 40 & 3.0 & 16 & 35 & 50 & $\mathrm{~T}$ & $\mathrm{KP}$ \\
\hline 019.S.3.a.b & Pelayanan umum dan sosial & 40 & 3.0 & 16 & 35 & 50 & $\mathrm{~T}$ & $\mathrm{KP}$ \\
\hline 003.K.1.a.b & Perkantoran Perdagangan dan jasa & 45 & 3.0 & 16 & 35 & 50 & $\mathrm{~T}$ & KP \\
\hline 004.K.1.a.b & Perkantoran Perdagangan dan jasa & 45 & 3.0 & 16 & 35 & 50 & $\mathrm{~T}$ & $\mathrm{KP}$ \\
\hline 010.C.1.a.b.d & Campuran & 50 & 2.0 & 4 & 35 & 50 & $\mathrm{D}$ & $\mathrm{KP}$ \\
\hline $\begin{array}{l}\text { Zona kuning di } \\
\text { belakang zona } \\
\text { komersil bagian } \\
\text { depan }\end{array}$ & Perumahan KDB Sedang-tinggi & 60 & 1.2 & 2 & 20 & - & $\mathrm{K}$ & $\mathrm{KP}$ \\
\hline \multicolumn{9}{|c|}{ Kelurahan Pondok Pinang, Kecamatan Kebayoran Lama } \\
\hline 002.K.1.a.b & Perkantoran Perdagangan dan jasa & 45 & 3.0 & 16 & 35 & 50 & $\mathrm{~T}$ & KP \\
\hline 012.K.1.b & Perkantoran Perdagangan dan jasa & 45 & 3.0 & 16 & 35 & 50 & $\mathrm{~T}$ & KP \\
\hline 011.K.1.b & Perkantoran Perdagangan dan jasa & 45 & 3.0 & 16 & 35 & 50 & $\mathrm{~T}$ & KP \\
\hline 009.K.1.b & Perkantoran Perdagangan dan jasa & 45 & 3.0 & 16 & 35 & 50 & $\mathrm{~T}$ & $\mathrm{KP}$ \\
\hline 010.K.1.b & Perkantoran Perdagangan dan jasa & 45 & 3.0 & 16 & 35 & 50 & $\mathrm{~T}$ & KP \\
\hline $\begin{array}{l}\text { Zona kuning di } \\
\text { belakang zona } \\
\text { komersil bagian } \\
\text { depan }\end{array}$ & Perumahan KDB Sedang - tinggi & 60 & 1.2 & 2 & 20 & - & $\mathrm{D} / \mathrm{K}$ & $\mathrm{KP}$ \\
\hline
\end{tabular}

Sumber: RDTR DKI Jakarta 2030, diolah penulis

Dari Tabel 3 terlihat intensitas bangunan untuk bangunan komersil, koefisien dasar bangunan (KDB) adalah antara 40\% - 45\%. Koefisien lantai bangunan (KLB) secara keseluruhan adalah 3.00 , dengan ketinggian bangunan (KB) adalah 16 lantai. Tipe bangunan untuk bangunan komersil secara keseluruhan adalah merupakam bangunan tunggal $(\mathrm{T})$.

Zona campuran yang terletak di ujung koridor JI. TB. Simatupang ruas perempatan Pondok Pinang - Perempatan Fatmawati persisnya di daerah perpotogan antara JI. TB SImatupang dengan JI. Raya Fatmawati, memiliki intensitas bangunan rendah yaitu dengan KDB 50, KLB 2, dan ketinggian bangunan 4 lantai. Zona perumahan yang berada di bagian belakang zona komersil, memiliki intensitas bangunan rendah yaitu dengan KDB 60, KLB 1.2, dan ketinggian bangunan 2 lantai. Tipe bangunan adalah kopel dan deret. Pada bangunan komersil, yaitu bangunan gedung perkantoran dan bangunan apartemen terdapat ketidak sesuaian ketinggian bangunan antara intensitas bangunan yang telah ditetapkan dalam RDTR dengan ketinggian bangunan gedung saat ini. Seperpti dijelaskan di atas bahwa menurut peraturan zonasi dan intensitas bangunan yaitu Perda DKI Jakarta No. 1 Tahun 2014 tentang Rencana Detail Tata Ruang dan Peraturan Zonasi, ketinggian bangunan yang diizinkan adalah 16 lantai. Sementara itu pada bangunan gedung eksisting, terdapat tiga gedung yang memiliki ketinggian bangunan lebih tinggi dari 16 lantai yaitu Gedung Metropolitan Tower dengan tinggi gedung adalag 22 lantai, Gedung South Quarter A dengan tinggi gedung adalah 22 lantai, dan gedung Palma Tower yang memiliki ketinggian 25 lantai. Tabel 4 merangkum kesesuaian ketinggian bangunan dengan peraturan zonasi.

Tabel 4. Kesesuaian Ketinggian Bangunan Komersil dengan RDTR dan Peraturan Zonasi

\begin{tabular}{ccccc}
\hline No & Nama Gedung Kantor & Tinggi $(\mathbf{l t})$ & $\begin{array}{c}\text { Ketinggian } \\
\text { menurut RDTR }\end{array}$ & Analisis \\
\hline 1 & Plaza Aminta & 9 & 16 & Sesuai \\
\hline
\end{tabular}




\begin{tabular}{ccccc}
\hline No & Nama Gedung Kantor & Tinggi (lt) & $\begin{array}{c}\text { Ketinggian } \\
\text { menurut RDTR }\end{array}$ & Analisis \\
\hline 2 & Lintas Arta & 11 & 16 & Sesuai \\
\hline 3 & Gedung Vetura & 9 & 16 & Sesuai \\
\hline 4 & Metropolitan Tower & 22 & 16 & Tidak Sesuai \\
\hline 5 & FIF & 16 & 16 & Sesuai \\
\hline 6 & South Quarter A & 22 & 16 & Tidak Sesuai \\
\hline 7 & Palma Tower & 25 & 16 & Tidak Sesuai \\
\hline
\end{tabular}

Sumber: olahan peneliti, 2020

Bangunan apartemen sebanyak 2 buah atau 2 tower juga memiliki ketinggian yang tidak sesuai dengan ketinggian bangunan yang ditetapkan dalam Perda DKI Jakarta No. 1 Tahun 2014 tentang Rencana Detail Tata Ruang dan Peraturan Zonasi. Apartemen Parama memiliki tinggi 18 lantai dan Apartemen Beverley Tower memiliki ketinggian bangunan 20 lantai seperti yang terlihat pada Tabel 5.

Tabel 5. Kesesuaian Ketinggian Bangunan Apartemen dengan RDTR dan Peraturan Zonasi

\begin{tabular}{ccccc}
\hline No & Nama Apartemen & Tinggi (It) & $\begin{array}{c}\text { Ketinggian } \\
\text { Menurut RDTR }\end{array}$ & Analisis \\
\hline 1 & Apartemen Parama & 18 & 16 & Tidak sesuai \\
\hline 2 & Beverly Tower & 20 & 16 & Tidak sesuai \\
\hline
\end{tabular}

Sumber: olahan peneliti, 2020

Dari uraian tersebut diatas dapat dilihat bahwa ketentuan intensitas bagunan di koridor JI. TB. SImatupang ruas perempatan Pondok Pinang - perempatan Fatmawati adalah tergolong sedang yaitu dengan ketinggian bangunan maksimum 16 lantai. Selain itu terdapat kecenderungan developer untuk membangun melebihi ketentuan ketinggian bangunan yang telah ditetapkan.

\section{Perkembangan Fungsi Komersil di JI. TB. Simatupang}

Penelitian ini melihat perkembangan koridor JI. TB. SImatupang ruas perempatan Pondok Pinang - Perempatan Fatmawati pada periode 2010 - 2020. Dari data yang berhasil dikumpulkan, sebagian besar bangunan gedung dan apartemen yang ada di koridor ini telah beroperasi sejak sebelum Tahun 2010. Bangunan gedung dan apartemen yang telah beroperasi sejak sebelum Tahun 2010 adalah Plaza AMinta, Gedung Ventura, Gedung FFI, apartemen Parama, dan apartemen Beverly. Sementara itu bangunan gedung yang relatif baru yang dibangun pada periode 2010-2020 adalah gedung Lintas Arta beroperasi 2014, gedung Metropolitan Tower beroperai tahun 2014, South Square beroperasi tahun 2015, dan Palma Tower beroperasi tahun 2014.

Dilihat dari data mulai beroperasinya gedung pada Tabel 6 nampak bahwa kecenderungan perkembangan kawasan koridor JI. TB. Simatupang menjadi kawasan komersil adalah telah berlangsung sejak awal Tahun 1990 an. Perkembangan kawasan permukiman penduduk di wilayah selatan Jakarta dan di pinggiran Jakarta wilayah selatan, perkembangan aksesibilitas kawasan yang dapat ditempuh dari berbaagai penjuru, serta adanya kenyataan bahwa wilayah Jakarta Pusat yang telah mulai penuh dan sulit memperoleh lahan kosong, diduga merupakan faktor-faktor yang mendorong perkembangan kawasan JI. TB SImatupang menjadi kawasan komesil. Walaupun berkembang sebagai kawasan komersil, namun arahan dalam RDTR dan Peraturan Zonasi yang memberikan batasan ketinggian bangunan hanya setinggi 16 lantai, dinilai masih mampu mengendalikan perkemangan fungsi kawasan wilayah selatan Jakarta sebagai kawasan resapan yang tidak terlalu padat seperti halnya wilayah Jakarta Pusat, Jakarta Barat dan Jakarta Utara. 
Tabel 6. Perkembangan Fungsi Komersil di JI. TB. Simatupang

\begin{tabular}{ccc}
\hline \multicolumn{1}{c}{ No } & Nama Gedung Kantor & Tahun Operasi \\
\hline A. & Bangunan Gedung & \\
\hline 1 & Plaza Amanta & 1994 \\
\hline 2 & Lintas Arta & 2014 \\
\hline 3 & Gedung Vetura & 1990 \\
\hline 4 & Metropolitan Tower & 2014 \\
\hline 5 & FIF & 2009 \\
\hline 6 & South Quarter A & 2015 \\
\hline 7 & Palma Tower & 2014 \\
\hline B. Bangunan Apartemen & \\
\hline 1 & Apartemen Parama & 1994 \\
\hline 2 & Apartemen Beverly & 1996
\end{tabular}

Sumber: survey lapangan, 2020

Peningkatan kualitas sarana transportasi dengan beroperasinya Trans Jakarta dan MRT, serta jalur Tol Lingkar Luar yang menhubungkan kawasan ini dengann kawasan lain di wilayah barat, timur, utara, dan selatan menjadi pendorong utama pekembangan kawasan. Aksesibilitas menuju bandara Soekarno Hatta yang sangat bagus, yaitu hanya sekitar 20 menit melalui jalur tol juga merupakan faktor penguat bagi dunia usaha untuk berkantor di sepanjang jalan TB SImatupang, khususnya di segmen perempatan Pondok Pinang - Perempatan Fatmawati.

\section{Perubahan Kawasan Permukiman di Belakang Kawasan Komersil}

Seperti telah dijelaskan di atas bahwa area di bagian belakang kawasan komersil adalah berfungi untuk zona perumahan, baik yang ada di wilayah Kelurahan Pondok Pinang, Kecamatan Kebayoran Lama, maupun di wilayah Kelurahan Cilandak Barat, Kecamatan Cilandak. Ketetapan fungsi ruang ini telah diatur dalam RDTR dan Peraturan Zonasi.

Karena telah diatur dengan RDTR dan Peratuan Zonasi, nampaknya sulit bisa terjadi perumahan penggunaan lahan dari kawasan permukiman atau perumahan menjadi bangunan komersil. Perubahan yang terjadi relatif terbatas dalam hal fungsi bangunan, misalnya perbahan dari bangunan rumah tinggal menjadi rumah kos, atau penggunaan bangunan rumah untuk membuka usaha yang bersifat mendukung kawasan. Perubahan fungsi rumah tinggal menjadi fungsi ekonomi ini antaranya disebabkan karena perkembangan kawasan sekitar yang membutuhkan usaha tersebut.

Tabel 7. Kecenderungan Perubahan dan/atau Peningkatan Fungsi Rumah

\begin{tabular}{|c|c|c|c|c|c|c|c|}
\hline \multirow{3}{*}{$\begin{array}{l}\text { No. } \\
1\end{array}$} & \multirow{2}{*}{\multicolumn{2}{|c|}{ Perubahan }} & \multirow{3}{*}{$\begin{array}{l}\text { Kepentingan/tujuan } \\
\text { Menambah ruang untuk } \\
\text { kebutuhan keluarga } \\
\text { Menambah kamar untuk } \\
\text { disewakan }\end{array}$} & \multicolumn{4}{|c|}{ Penggunaan } \\
\hline & & & & \multirow{2}{*}{$\begin{array}{l}\text { Sdr } \\
V\end{array}$} & \multirow{2}{*}{$\begin{array}{l}\text { TBS } \\
\mathrm{V}\end{array}$} & \multirow{2}{*}{$\begin{array}{l}\text { Non- } \\
\text { TBS } \\
\mathrm{V}\end{array}$} & \multirow{2}{*}{$\begin{array}{l}\text { SKTR } \\
-\end{array}$} \\
\hline & Rumah 1 lantai & $\begin{array}{l}\text { Rumah } \\
\text { tingkat }\end{array}$ & & & & & \\
\hline 2 & Rumah tinggal & Rumah kos & Usaha rumah kos & & $\mathrm{V}$ & v & - \\
\hline 3 & Rumah tinggal & $\begin{array}{l}\text { Warung } \\
\text { sembako }\end{array}$ & $\begin{array}{l}\text { Menambah penghasilan } \\
\text { keluarga }\end{array}$ & - & - & - & $\mathrm{V}$ \\
\hline 4 & Rumah tinggal & $\begin{array}{l}\text { Warung } \\
\text { makan }\end{array}$ & $\begin{array}{l}\text { Menambah penghasilan } \\
\text { keluarga }\end{array}$ & - & $\mathrm{V}$ & v & $\mathrm{v}$ \\
\hline
\end{tabular}

Keterangan :

Sdr : Digunakan sendiri

TBS : Karyawan dari JI. TB Simatupang

Sumber: olahan penulis, 2020
Non-TBS: Karyawan bukan dari JI. TB Simatupang

SKTR : Penduduk sekitar 
Hasil pengamatan lapangan menunjukkan kecenderungan perubahan kawasan permukiman di belakang koridor JI. TB. Simatupang Ruas Perempatan Pondok Pinang - Perempatan Fatmawati seperti disajikan pada Tabel 7. Tabel ini menunjukkan bahwa secara keseluruhan terjadi perubahan fungsi bangunan dari bangunan rumah menjadi fungsi rumah kos, warung makan, bengkel, mini market, dan café. Tidak terjadi perubahan penggunaan lahan karena penggunaan lahan di kawasan permukiman di belakang Koridor JI. TB. Simatupang telah diikat dengan RDTR dan Peraturan Zonasi yaitu sebagai kawasan permukiman. Keberadaan bangunan mini market yang telah merubah bangunan rumah menjadi bangunan mini market lebih bersifat sebagai kegiatan yang menunjang bangunan perumahan dalam bentuk penyediaan kebutuhan pokok sehari-hari. Sama halnya dengan kegiatan minimarket, perubahan rumah menjadi café juga bersifat melengkapi kebutuhan sarana sosialisasi bagi penghuni. Menurut keterangan karyawan café, kebanyakan tamu café adalah dari lingkungan perumahan sekitar, atau tamu dari lingkungan perumahan sekitar tersebut.

Perkembangann koridor Jl. TB. Simatupang menjadi kawasan komersil telah memberikan dampak terhadap harga lahan di kawasan belakangnya. Harga lahan yang naik idealnya perlu iikuti dengan pemanfaatan lahan yang dapat memberikan nilai tambah yang tinggi, yaitu untuk bangunan komersil. Namun demikian untuk kawasan perumahan di belakang JI. TB Simatupang koridor Perempatan Pondok Pinang - Perempatan Fatmawati telah ditetapkan penggunaannya untuk kawasan permukiman, sehingga tidak mungkin atau sangat sulit untuk berubah menjadi kawasan komersil.

Beroperasinya bus Trans Jakarta dan moda transportasi massal MRT memberikan pengaruh yang sangat nyata terhadap aksesibilitas kawasan. Perhubungan kawasan ini dengan kawasan pusat kegiatan lain di Jakarta sangat lancar dengan durasi waktu hingga pukul 24.00. Kondisi ini juga memberikan pengaruh terhadap nilai lahan yang ada di dalam kawasan. Kecenderungan pemilik lahan juga mendukung untuk perubahan penggunaan lahan. Mereka cenderung ingin menjual lahannya dengan harga yang mahal dan pindah ke kawasan disebelah selatan Jakarta, seperti Pondok Cabe, Pamulang, atau Sawangan dan Parung untuk bisa memperoleh tanah dengan harga lebih murah dengan lingkungan yang masih bagus. Kelebihan uang akan dapat digunakan untuk kepentingan lain yang mendukung kehidupan keluarganya.

Implementasi peraturan dalam hal ini RDTR dan Peraturan Zonasi telah cukup ketat mengendalikan fungsi ruang di dalam kawasan ini sehingga kecenderungan perubahan penggunaan lahan sulit terjadi. Kondisi ini berbeda dengan kawasan pinggir JI. TB Simatupang yang masih terhadi penyimpangan implementasi RDTR terkait dengan ketinggian bangunan yang melebihi dari ketinggian yang telah ditetapkan dalam RDTR dan Peraturan Zonasi.

Tabel 8. Bentuk Perubahan Bangunan Permukiman di Kawsan Belakang Koridor JI. TB. Simatupang Ruas Perempatan Pondok Pinang - Perempatan Fatmawati

\begin{tabular}{|c|c|c|c|c|c|}
\hline \multirow[b]{2}{*}{ No. } & \multirow[b]{2}{*}{ Bangunan } & \multicolumn{3}{|c|}{ Perubahan yang Terjadi } & \multirow[b]{2}{*}{ Keterangan } \\
\hline & & $\begin{array}{c}\text { Fungsi } \\
\text { Bangunan }\end{array}$ & $\begin{array}{l}\text { Guna } \\
\text { Lahan }\end{array}$ & $\begin{array}{c}\text { Bentuk } \\
\text { Bangunan }\end{array}$ & \\
\hline 1. & Rumah Kos & $\sqrt{ }$ & - & $\sqrt{ }$ & $\begin{array}{l}\text { Bentuk bangunan berubah } \\
\text { menjadi bangunan bertingkat } \\
\text { model rumah kos }\end{array}$ \\
\hline 2. & $\begin{array}{l}\text { Warung } \\
\text { Makan }\end{array}$ & $\mathrm{V}$ & - & - & $\begin{array}{l}\text { Pemanfaatan ruang bagian depan } \\
\text { rumah untuk ruang warung } \\
\text { makan. }\end{array}$ \\
\hline 3. & Bengkel & $\sqrt{ }$ & - & - & $\begin{array}{l}\text { Tidak ada perubahan bentuk } \\
\text { bangunan, hanya perubahan } \\
\text { fungsi ruang di bagian depan }\end{array}$ \\
\hline
\end{tabular}




\begin{tabular}{|c|c|c|c|c|c|}
\hline \multirow[b]{2}{*}{ No. } & \multirow[b]{2}{*}{ Bangunan } & \multicolumn{3}{|c|}{ Perubahan yang Terjadi } & \multirow[b]{2}{*}{ Keterangan } \\
\hline & & $\begin{array}{c}\text { Fungsi } \\
\text { Bangunan }\end{array}$ & $\begin{array}{l}\text { Guna } \\
\text { Lahan }\end{array}$ & $\begin{array}{c}\text { Bentuk } \\
\text { Bangunan }\end{array}$ & \\
\hline & & & & & $\begin{array}{l}\text { rumah untuk ruang bengkel } \\
\text { motor. }\end{array}$ \\
\hline 4. & Mini Market & V & - & V & $\begin{array}{l}\text { Bentuk bangunan dirubah menjadi } \\
\text { bangunan tanpa kamar untuk } \\
\text { ruang berdagang mini market }\end{array}$ \\
\hline 5. & Café & V & - & V & $\begin{array}{l}\text { Bentuk bangunan dirubah menjadi } \\
\text { bangunan tanpa kamar untuk } \\
\text { ruang berdagang kopi }\end{array}$ \\
\hline
\end{tabular}

Sumber: olahan penulis, 2020

Selain perubahan fungsi bangunan, juga terjadi kecenderungan perubahan bangunan dalam arti penambahan lantai bangunan dengan cara menambah ketinggian bangunan. Banyaknya bangunan rumah tinggal berupa perumahan swadaya yang rata-rata memiliki ketinggian 2 lantai. Menurut informasi responden, semula bangunan rumah yang ada di area ini merpakan bangunan satu lantai.

Perbaikan kondisi ekonomi keluarga dan adanya tuntutan kebutuhan ruang membuat pemilik rumah cenderung menambah lantai dengan menambah ketinggian bangunan. Penambahan lantai bangunan juga terkait dengan upaya menambah ruang untuk tujuan disewakan

\section{Pengaruh Perkembangan Kawasan Komersil JI. TB Simatupang Terhadap Kawasan Permukiman di Belakangnya}

Telah dijelaskan di atas bahwa karena telah diikat di dalam RTRW dan RDTR serta Peraturan Zonasi, maka sulit atau tidak terjadi perubahan fungsi ruang atau lahan di belakang kawasan belakang JI. TB SImatupang. Perubahan yang terjadi adalah bersifat peningkatan fungsi rumah sebagai rumah tinggal menjadi rumah kos atau penambahan fungsi menjadi fungsi tempat usaha, terutama sebagai warung sembako atau warung makan.

Perubahan fungsi ini diduga tidak semata-mata disebabkan karena peningkatan bangunan komersil di JI. TB Simatupang, namun karena posisi kawasan yang strategis dengan aksesibilitas yang baik dan terhubung ke berbagai wilayah bisinis di Jakarta. Sepeprti diketahui bahwa wilayah study memiliki akses dengan kawasan komersil Pondok Indah, Blok M, Kampung Rambutan, bahkan kea rah Jalan Buncit Raya dengan jaringan transportasi umum yang baik.

Usaha rumah kos yang ada tidak hanya ditinggali oleh orang-orang yang bekerja di kawasan TB SImatupang, namun juga mereka yang bekerja di kawasan bisnis lainnya, di Jakarta Selatan, Jakarta Pusat, Jakartai, dan Jakarta Barat. Dari hasil wawancara dengan penjaga rumah kos diketahui bahwa terdapat penyewa yang bekerja di Kawasan Kebon Jeruk yang merupakan wilayah Jakarta Barat. Di sisi lain, banyak karyawan yang bekerja di Kawasan JI. TB SImatupang yang berasal dari daerah lain seperti Jakarta Timur, Jakarta Pusat, Jakarta Barat, dan dari daerah sekitar Jakarta seperti dari Tangerang, Tangerang Selatan, Depok, dan dari wilayah Bogor.

Dari uraian di atas bisa dilihat bahwa peningkatan kawasan komersil JI. TB Simatupang Ruas Perempatan Pondok Pinang-Perempatan Fatmawati tidak dominan mendorong perubahan kawasan belakangnya karena kondisi aturan Rencana Detail Tata Ruang dan Peraturan Zonasi yang mengaturnya. Asumsi bahwa perubahan kawasan komersil Jl. TB. Simatupang koridor Perempatan Pondok Pinang - Perempatan Fatmawati menimbulkan dampak terhadap kawasan permukiman di belakangnya tidak terbukti nyata. Diasumsikan perkembanan kawasan komersi di sepanjang JI. TB Simatupang dengan berdirinya bangunan office tower dan apartemen akan 
mengundang tenaga kerja untuk bekerja di kawasan ini. Sebagian dari tenaga kerja akan cenderung mencari tempat tinggal yang dekat dengan tempat kerjanya yaitu di kawasan permukiman di belakang J. TB. Simatupang, sehingga diduga akan mempengaruhi permukiman di kawasan belakang JI. TB Simatupang. Kenyataan lapangan menunjukkan bahwa pekerja di kawasan JI. TB Simatupang sebagian besar berasal dari wilayah permukiman di sekitarnya. Seperti ditunjukkan pada Gambar 5 bahwa kawasan ini terhubung dengan kawasan permukiman sekitar yaitu arah Kp Rambutan di wilayah Timur, wilayah Pondok Labu, Cinere di sebelah Selatan, wilayah Blok M, Kebayoran, dan Pondok Indah di sebelah utara, dan wilayah Ciputat, Pondok Cabe di sebelah Baratnya.

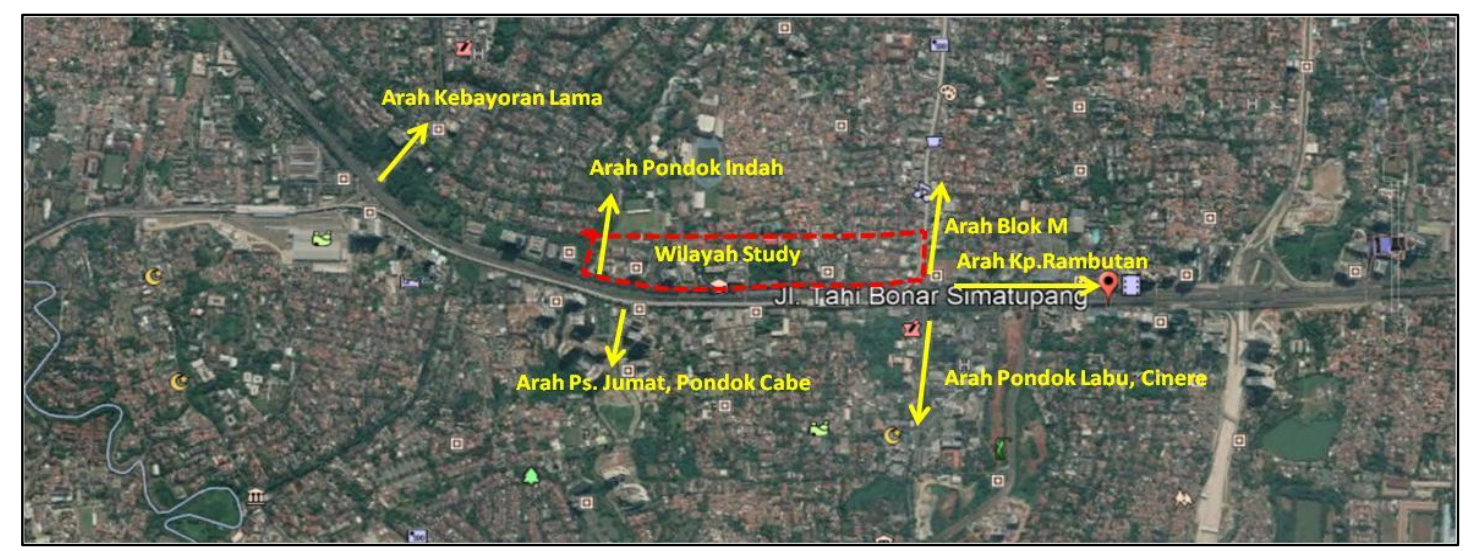

Gambar 5. Keterhubungan Kawasan Study dengan Wilayah Permukiman di Sekitarnya Sumber: olahan penulis, 2020

\section{KESIMPULAN DAN SARAN}

\section{Kesimpulan}

Pada periode Tahun 2010-2020 penambahan gedung komersil di Koridor JI. TB. Simatupang Ruang Perempatan Pondok Pinang - Perempatan Fatmawati relatif sedikit yaitu Gedung Perkantoran Lintas Artha beroperasi Tahun 2014, Gedung Metropolitan Tower beroperasi Tahun 2014, Gedung Palma Tower beroperasi Tahun 2014, dan Gedung South Quarter A beroperasi Tahun 2015. Pada periode Tahun 2010-2020 tidak ada penambahan bangunan apartemen di Koridor J. TB. Simatupang Ruang Perempatan Pondok Pinang - Perempatan Fatmawati. Hanya terdapat 2 (dua) gedung apartemen yaitu Apartemen Parama yang beroperasi sejak Tahun 1994 dan Apartemen Beverley yang beroperasi sejak Tahun 1996.

Ditinjau dari ketentuan dalam Perda DKI Jakarta No. 1 Tahun 2014 tentang Rencana Detail Tata Ruang dan Peraturan Zonasi, bangunan gedung komersil tersebut tidak sesuai dengan RDTR dan Peraturan Zonasi. Ketinggian bangunan di zona ini menurut RDTR adalah 16 lantai, sementara itu Gedung Metropolitan Tower memiliki ketinggian 22 lantai, South Quarter A memiliki ketinggian 22 lantai, dan Palma Tower memiliki ketinggian 25 lantai. Dua bangunan apartemen yaitu Apartemen Parama dan Apartemen Beverly Tower juga memiliki ketinggian yang tidak sesuai dengan RDTR, namun bangunan ini telah beroperasi jauh sebelum penetapan Peraturan Daerah DKI Jakarta No. 1 Tahun 2014, sehingga kemungkinan dapat dianggap tidak melanggar.

Di bagian belakang, selain tumbuh usaha rumah kos, juga terdapat perubahan fungsi bangunan antara lain untuk tempat kos, warung sembako, warung makan, dan café. Perkembangan rumah kos di bagian belakang Koridor Jalan TB. Simatupang Ruas Perempatan Pondok Pinang Perempatan Fatmawati tidak semata-mata terkait dengan perkembangan bangunan komersil dan apartemen yang ada di koridor ini. Posisi lokasi yang strategis ikut mendorong perkembangan usaha rumah kos. Lokasi ini terhubung kearah Terminal Kampung Rambutan 
dibagian Timur, kearah Blok M di bagian Utara, kearah Pasar Senen melalui Jl. Buncit Raya, serta kearah Barat melalui Jalan Kebayoran Lama dan Jalan Panjang.

Karyawan yang bekerja di perkantoran koridor JI. TB. Simatupang ruas Perempatan Pondok Pinang - Perempatan Fatmawati pada umumnya berasal dari wilayah di luar koridor ini. Mereka bermukiman di kawasan sebelum selatan dan barat melalui jalan akses JI. Pondok Cabe, Jl. Ciputat Raya, dari arah timur menggunak akses Jl. TB. SImatupang dan dari arah utara menggunakan akses Jl. Raya Fatmawati.

\section{Saran}

Guna mempertahankan fungsi ruang yang sesuai dengan Recana Tata Ruang, maka perlu dilakukan tindakan di antaranya sebagai berikut:

a. Pengendalian bangunan di koridor J. TB. Simatupang agar tidak lepas dari ketentuan yang telah diatur dalam RDTR dan Peraturan Zona, khususnya terkait dengan ketinggian bangunan. Ketinggian maksimal bangunan menurut RDTR adalah 16 lantai, sementara itu masih ada bangunan yang ketinggiannya lebih dari 16 lantai.

b. Pengendalian fungsi ruang pada area permukiman di belakang koridor Jl. TB. Simatupang. Secara umum fungsi ruangnya adalah sebaai kawasan permukiman. Perlu dikendalikan agar tidak terjadi konversi dari permukiman menjadi penggunaan komersil.

\section{REFERENSI}

Bahana W.W. dan Rachmawati R. (2011). Evaluasi Dampak Infrastruktur Jalan Terhadap Perkembangan Fisik Kota dan Kegiatan Perdagangan/Jasa di Kawasan Koridor Jalan Llngkar Soekarno Hatta. Palembang.

Charles, C. (1933). Centrifugal and Centripetal Force in Urban Geography. University of Chicago. Jayadinata. (1992). Tata Guna Tanah Dalam Perencanaan Perdesaan, Perkotaan dan Wilayah. Bandung: ITB

Habraken, J.N. (1983). Transformation of Site. Massachusettes, USA.

Hendarto, R.M. (1997). Teori Perkembangan dan Pertumbuhan Kota.

Harjanti A. (2002). Identifikasi Faktor-faktor Penyebab Perubahan Penggunaan Lahan Permukiman Menjadi Komersil di Kawasan Kemang, Jakarta Selatan. Jurusan Perencanaan Wilayah dan Kota, Universitas Diponegoro.

Moekijat. (1997). Adminsitrasi Perkantoran. Bandung: Mandar Maju.

Prajudi, A. (1982). Administrasi dan Manajemen Umum. Jakarta: Ghalia Indonesia.

Prasetyo H. A. (2016). Perubahan Peruntukan Kawasan Dalam Perpektif Penataan Ruang (Study di Mojokerto). Malang: Magister Ilmu Hukum Universitas Brawijaya

Parliana, D, Kurniadilaga, A, dan Megakusumah OR. (2017). Transformasi Kawasan Komersial Cihampelas Walk (Ci-Walk) Bandung.

Rapoport, A. (1969). House Form and Culture. New York: Prentice-Hall.

Jarwa, P.S.H. (2015). Perkembangan Spasial Permukiman di Kawasan Tumbuh Cepat: Study Kasus Desa Ulbulmartani, Kecamatan Ngemplak, Kabupaten Sleman. Jurnal Teknik SIpil 1(17), 7-16

Raus H. dan Adinatta. (2011). Identifikasi PRoses dan Dampak Perubahan Fungsi Perumahan Menjadi Komersil di Koridor Wolter Monginsidi dam Kawasan Pasar Santa, Kecamatan Kebayoran Baru. Jurnal Planesia 2(1).

Suryani, T.A. dan Rahdriawan, M. (2013). Kajian Perkembangan Fisik dan Tipologi Kawasan Permukiman di Pusat Pertumbuhan Kecamatan Tembalang, Kota Semarang. Jurnal Pengembangan Kota 1(2), 108-117.

Samadikun, B.P., Sudibyakto, S, Setiawan, B., dan Rijanta R. (2014). Dampak Perkembangan Kawasan Pendidikan di Tembalang Semarang. Jurnal Manusia dan Lingkungan 2(3), 366-376. 
Badan Pusat Statistik Jakarta Selatan. (2019). Jakarta Selatan Dalam Angka Tahun 2019. DKI Jakarta.

Badan Pusat Statistik Jakarta Selatan. (2019). Kecamatan Kebayoran Lama Dalam Angka Tahun 2019. DKI Jakarta.

Badan Pusat Statistik Jakarta Selatan. (2018). Kecamatan Kebayoran Lama Dalam Angka Tahun 2018. DKI Jakarta.

Badan Pusat Statistik Jakarta Selatan. (2019). Kecamatan Cilandak Dalam Angka Tahun 2019. DKI Jakarta.

Badan Pusat Statistik Jakarta Selatan. (2018). Kecamatan Cilandak Dalam Angka Tahun 2018. DKI Jakarta.

Berita Properti. (2014). Gedung perkantoran baru di daerah tb simatupang. Diakses pada 12 Juni 2020 dari https://www.rumah.com/berita-properti/2014/2/6935/ini-dia-15gedung-kantor-baru-di-tb-simatupang 